\title{
CAPOEIRA E ENSINO DA CULTURA AFRO-BRASILEIRA: ANÁLISE DO MATERIAL DO ALUNO - CICLO II
}

\author{
Irís de França Britto ${ }^{1}$, Wagner Aparecido Caetano ${ }^{2}$, Arilda Inês Miranda Ribeiro ${ }^{3}$ \\ ${ }^{1,2}$ Universidade do Oeste Paulista - UNOESTE. Curso de Educação Física, Presidente Prudente - SP. ${ }^{3}$ Universidade \\ Estadual Paulista - FCT/UNESP. Grupo de Pesquisa em Educação, Cultura, Memória e Arte (GPECUMA), Presidente \\ Prudente-SP. E-mail: íris kizy@hotmail.com
}

\section{RESUMO}

O presente estudo teve por objetivo elaborar uma análise sobre a realidade do ensino de cultura africana nas instituições escolares dentro da grade curricular do Ensino Fundamental, construindo um entendimento sobre a importância da Lei no 10.639/2003 (temática afro-brasileira) para o ensino brasileiro. Discutiu-se a possibilidade de sua aplicação via aulas de Educação Física, materializada no ensino da capoeira. A metodologia adotada apoiou-se na abordagem qualitativa elaborando uma pesquisa bibliográfica e análise do material didático do Ensino Fundamental Ciclo II do Governo do Estado de São Paulo. Concluímos assim, que a capoeira está inserida na grade curricular do Ensino Fundamental - Ciclo II, na $8^{\circ}$ série $/ 9^{\circ}$ ano, porém sua prática ainda não compreende todos os aspectos necessários para a efetivação da lei.

Palavras-chave: Ensino Fundamental; Educação Física; Capoeira

\section{CAPOEIRA AND TEACHING OF AFRO-BRAZILIAN CULTURE: ANALYSIS OF MATERIAL STUDENT - CYCLE II}

\begin{abstract}
This study aimed to prepare an analysis on the reality of the teaching of African culture in schools within the curriculum of the Elementary School, building an understanding of the importance of Law 10.639/2003 (African - Brazilian theme) for the Brazilian education and discussing the possibility of applying via the Physical Education classes, embodied in the teaching of capoeira. The methodology was based on the Qualitative Approach by developing a bibliogaphic resarch and analysis of the teaching material of elementary education - Cycle II of the State of São Paulo . We concluded that capoeira is embedded in the curriculum of primary education cycle - II in 8th grade / 9 th, but its practice still does not cover all necessary aspects for an effective law.
\end{abstract}

Keywords: Elementary School; Physical Education; Capoeira. 


\section{INTRODUÇÃO}

A Educação Física escolar, em seu componente curricular, presente nos Parâmetros Curriculares Nacionais, tem como objeto de estudo a cultura corporal de movimento que integra os jogos, lutas, danças, esportes ginásticas e outras práticas, visando a possibilitar uma formação integral e plena ao aluno.

Essa integração se dá não somente de forma material, mas articula-se com a sociedade nas dimensões afetivas, cognitivas e socioculturais dos alunos preparando-os para o exercício da cidadania (PCN, 1998, p. 15; apud EHRENBERG e FERNANDES, 2012).

Esse artigo visa a responder à seguinte pergunta: de acordo com a obrigatoriedade da lei no 10.639/2003 (temática afro-brasileira), após sua sanção, é possível aplicá-la via aulas de Educação Física, materializada no ensino da capoeira?

A capoeira é uma forma de inserir cultura afro-brasileira na grade escolar, uma vez que, a Educação Física permite que se vivenciem diferentes práticas corporais advindas das mais diversas manifestações culturais (BRASIL, 1998, p. 38).

A principal finalidade deste trabalho é discutir e apresentar novos caminhos para a implantação e efetivação da Lei noㅡ 10.639/2003 via aulas de Educação Física, dentro da grade curricular do Ensino
Fundamental Ciclo - II materializada no ensino da capoeira.

A relevância desse trabalho pode ser considerada de irrefutável indispensabilidade, pois a capoeira caracteriza-se, num teor político, socializador e promotor da igualdade racial, na medida em que promove a integração dos sujeitos numa perspectiva homogênea e harmoniosa consigo e com o próximo (BONFIM, 2010).

A metodologia utilizada neste trabalho apoia-se na abordagem qualitativa que de acordo com Severino (2007), permite um trabalho que seja:

[...] fruto de um esforço do próprio pesquisador. Autonomia esta que não significa desconhecimento ou desprezo da contribuição alheia, mas, ao contrário, capacidade de inter-relacionamento enriquecedor, portanto dialético, com outros pesquisadores, com os resultados de outras pesquisas, e até mesmo com os fatos. [...] é preciso ter até mesmo um pouco de audácia, ou seja, arriscar-se a avançar ideias novas, eventualmente nascidas de suas intuições pessoais (SEVERINO, 2007, p. 216).

Utilizando-se das técnicas de pesquisa bibliográfica (GIL, 2008), com base em artigos científicos, livros e em rede (internet), análise do material didático do Ensino Fundamental - Ciclo II do Governo do Estado de São Paulo 
e síntese dos dados conceituais obtidos, os quais serão interpretados pelos autores a fim de elucidar melhor sobre o tema proposto, observando a aplicabilidade do ensino da história e cultura afro-brasileira no contexto escolar na disciplina de Educação Física.

Também é pertinente, com o intuito de esclarecer a metodologia adotada neste trabalho de pesquisa, citar Patton (1999) que nos esclarece sobre a dimensão de campo da pesquisa que contém dados qualitativos:

[...] descrições detalhadas de situações, eventos, pessoas, interações e comportamentos

observados; citações literais do que as pessoas falam sobre suas experiências, atitudes, crenças e pensamentos; trechos ou íntegras de documentos, correspondências, atas ou relatórios de casos (PATTON apud ALVES-MAZZOTTI, 1999, p. 132).

Para a possibilidade da aplicação da temática afro-brasileira proposta pela Lei $n$ 으 10.639/2003, no currículo, foram analisados os conteúdos contidos nos "Cadernos do Aluno"1 para a disciplina de Educação Física do Ensino Fundamental - ciclo II que compreende do 6으 ao 9으 ano.

\footnotetext{
${ }^{1}$ Proposta Curricular do Estado de São Paulo, criada em 2007. Consiste em um conjunto de livros didáticos organizados e/ou divididos por bimestres, séries (anos) e disciplinas, que servem como um conteúdo de apoio.
}

\section{EMBASAMENTO TEÓRICO}

A história do negro no mundo ocidental, principalmente a partir do neocolonialismo do século XIX, é marcada pela luta contra o preconceito racial, luta contra o silêncio da sociedade no que diz respeito à quebra das barreiras da discriminação (CAVALLEIRO, 2007).

De acordo com Oliveira Silva (2012) o Brasil enxerga no branqueamento a possibilidade de apagar o sangue negro que corria nas veias da mestiça população brasileira. Segundo Albuquerque (2006), os negros foram trazidos para o Brasil com o objetivo de trabalhar na agricultura, com destaque para a atividade açucareira e na mineração, sendo assim essenciais, enquanto mão de obra, para a manutenção da economia colonial.

Os povos vindouros da África sofreram todo tipo de repressão e opressão, por serem tidos como uma raça inferior em relação à branca (REIS, 2009).

O racismo subentende ou afirma claramente que existem raças puras, que estas são superiores às demais e que tal superioridade autoriza uma hegemonia política, econômica e histórica, pontos de vista contra os quais se levantam objeções consideráveis. No Brasil, ele é decorrente principalmente pela condição ao que a etnia africana foi submetida. 
O Racismo e as práticas discriminatórias

disseminadas no cotidiano brasileiro não representam simplesmente uma herança do passado. O racismo vem sendo recriado e alimentado ao longo de toda a nossa história. Seria impraticável desvincular as desigualdades observadas atualmente dos quase quatro séculos de escravismo que a geração atual herdou (SILVA, 2007, apud BRASIL, 2001).

Identificar-se como negro, no Brasil, é extremamente difícil e doloroso. Diante disso, Reis (2009) relembra a realidade social brasileira que tem colocado, historicamente, numa condição de inferioridade as pessoas de pele escura diante de outras pessoas que não têm, por exemplo, os mesmos fenótipos. A pessoa negra foi sempre sinônimo de escravizada, subordinada, marginalizada, entre tantas outras expressões e situações que são apresentadas diante da sociedade numa condição de inferiorizadas. Para caracterizar essa afirmativa, definimos identidade como o conjunto de caracteres próprios e exclusivos (OLIVEIRA , 2012, p. 25).

É preciso reconhecer que a cultura negra contribuiu para a pluralidade e formação cultural do Brasil, como afirma Abramowicz que:

Em nosso trabalho cotidiano, incorporar o discurso da diferença não como um desvio, mas como algo que enriquece nossas práticas e as relações entre as crianças, possibilitando, desde cedo,o enfrentamento de práticas de racismo, a construção de posturas mais abertas às diferenças $e$, consequentemente, a construção de uma sociedade mais plural. (ABRAMOWICZ et al., 2006, p. 74).

Diante dessa contribuição, faz-se necessária a inserção de práticas educativas que promovam a inclusão da cultura negra no Brasil, pois os mesmos sofreram danos físicos, sociais, morais e psicológicos. Para que essa cultura seja dissolvida e se difunda em todos os campos, deve ser iniciada no âmbito escolar, uma vez que ele é a base para a formação do cidadão.

A LDB, 9.394/96 no seu Art. 10 declara que:

A educação abrange os processos formativos que se desenvolvem na vida familiar, na convivência humana, no trabalho, nas instituições de ensino e pesquisa, nos movimentos sociais e organizações da sociedade civil e nas manifestações culturais (BRASIL, 1995).

De acordo com Oliveira Silva (2012), a lei $n$ ‥ 10.639/2003 alterou a Lei de Diretrizes e Bases (Lei no. 9394/1996) e tornou obrigatório o ensino da História e Cultura 
Afro-brasileira no Ensino Fundamental e Médio.

A prática dessa lei deve ser tratada em todos os campos da educação, inclusive a Educação Física que, por sua vez, não é somente incluída como área de saúde, mas associada também às ciências humanas e às da educação, pois, em tais áreas, assume uma dimensão pedagógica (COSTA e NASCIMENTO, 2006).

Em seu art. 26, § 3으, a LDB (Lei no 9.394/96) estabelece a disciplina de Educação Física como um componente curricular obrigatório da educação básica, ademais ela não é uma das disciplinas responsáveis pela inclusão do ensino da história e cultura afro-brasileira, como assegura o art. 26-A , § 2으, que "os conteúdos referentes à História e Cultura Afro Brasileira serem ministrados em especial nas áreas de Educação Artística e de Literatura e História Brasileira." (BRASIL, 2003).

Entretanto, no art 26-A, $\S 20$, também consta que esse conteúdo deve ser ministrado no âmbito de todo o currículo escolar, o que orienta a percorrer por todas as disciplinas, incluindo a Educação Física.

Com base nos PCN, entende-se que a Educação Física escolar não pode isentar-se desta empreitada em busca pela aplicação da Lei $n^{\circ} 10.639 / 2003$, tornando-se necessária a apresentação de atividades ou estratégias de ação para viabilizar o desenvolvimento da temática em questão a partir de vivências no âmbito escolar (SOUZA e FERRAZ, 2007).

Souza (2012) afirma que a inclusão desse tema no currículo escolar propicia a possibilidade de um trabalho interdisciplinar, enriquecendo e dando um maior significado à aprendizagem dos alunos.

[...] Observar, analisar, compreender essas atitudes corporais são atividades que podem ser desenvolvidas juntamente com projetos de História, Geografia e Pluralidade Cultural. Além da análise dos diferentes hábitos, pode-se incluir a questão da postura dos alunos na escola: as posturas mais adequadas para fazer determinadas tarefas e para diferentes situações (BRASIL, 1998. p. 68).

Darido (2005) sustenta que a Educação Física é uma prática pedagógica que trata da cultura corporal de movimento e que possui como objetivo introduzir e integrar os alunos, formando cidadãos que poderão desfrutar, compartilhar e modificar as manifestações que caracterizam essa área, que são os jogos, as danças, as lutas, os esportes e as ginásticas (BRASIL, 1998, p 70).

A proposta dos Parâmetros Curriculares Nacionais indicam como objetivos do Ensino Fundamental que os alunos sejam capazes de:

- compreender a cidadania 
participação social e política, assim como exercício de direitos e deveres políticos, civis e sociais, adotando, no dia-adia, atitudes de solidariedade, cooperação e repúdio às injustiças, respeitando o outro $e$ exigindo para si o mesmo respeito;

- posicionar-se de maneira crítica, responsável e construtiva nas diferentes situações sociais, utilizando o diálogo como forma de mediar conflitos e de tomar decisões coletivas;

- conhecer

características

fundamentais do Brasil nas dimensões sociais, materiais e culturais como meio para construir progressivamente a noção de identidade nacional e pessoal e o sentimento de pertinência ao país;

- conhecer e valorizar a pluralidade do patrimônio sociocultural brasileiro, bem como aspectos socioculturais de outros povos e nações, posicionando-se contra qualquer discriminação baseada em diferenças culturais, de classe social, de crenças, de sexo, de etnia ou outras características individuais e sociais;

- perceber-se integrante, dependente e agente transformador do ambiente, identificando seus elementos e as interações entre eles, contribuindo ativamente para a melhoria do meio ambiente;

- desenvolver

0 conhecimento ajustado de si mesmo e o sentimento de confiança em suas capacidades afetiva, física, cognitiva, ética, estética, de inter relação pessoal e de inserção social, para agir com perseverança na busca de conhecimento e no exercício da cidadania;

- conhecer o próprio corpo e dele cuidar, valorizando e adotando hábitos saudáveis como um dos aspectos básicos da qualidade de vida e agindo com responsabilidade em relação à sua saúde e à saúde coletiva;

- utilizar as diferentes linguagens - verbal, musical, matemática, gráfica, plástica e corporal - como meio para produzir, expressar e comunicar suas idéias, interpretar e usufruir das produções culturais, em contextos públicos e privados, atendendo a diferentes intenções e situações de comunicação;

- $\quad$ saber utilizar diferentes fontes de informação e recursos tecnológicos para adquirir e construir conhecimentos;

- questionar a realidade formulando-se problemas e tratando de resolvê-los, utilizando para isso o pensamento lógico, a criatividade, a intuição, a capacidade de análise crítica, selecionando procedimentos 
verificando sua adequação. (BRASIL, 1998, p. 6-7).

Há diversas formas de se oportunizar o aprendizado da História e Cultura Afrobrasileira na Educação Física escolar, neste trabalho a capoeira é o nosso objeto de estudo.

A Capoeira apresenta traços de jogo, dança, religião e luta, sendo hoje considerada como uma arte essencialmente brasileira. Nela, podemos desenvolver conteúdos lúdicos (como jogo e suas variações), religiosos (nos cantos durante a roda, por exemplo), dança (através da ginga e dos movimentos de floreio) e defesa pessoal (por meio dos movimentos de ataques e defesas presentes na Capoeira) (ARAÚJO e FONSECA, 2010, p.3).

De acordo com Ehrenberg (apud SILVA; HEINE, 2008), ao ministrar o conteúdo capoeira nas aulas de Educação Física poderemos facilitar a sociabilização, ou seja, uma capoeira que "sem perder as suas características originais e essenciais, é reconstruída e reinventada a partir dos referenciais educacionais". (SILVA; HEINE, 2008).

Além dos objetivos para o Ensino Fundamental é preciso salientar que os três blocos de conteúdos dos PCN (BRASIL, 1998), conhecimentos sobre o corpo, esportes, jogos, lutas e ginásticas e atividades rítmicas e expressivas, articulam-se entre si, e a capoeira integra também esses três blocos, além de estimular e desenvolver aptidões físicas naturais, fornecer o desenvolvimento das qualidades físicas, estimular a capacidade de expressão individual por meio de movimentos criativos, favorecer a socialização, contribuir para o desenvolvimento das habilidades motrizes básicas (coordenação, lateralidade, organização de espaço-tempo, e expressão corporal), como também contribuir nas capacidades motrizes básicas (resistência, flexibilidade, agilidade e destreza) (OLIVEIRA 2012 apud SANTOS, 1990; SÃO PAULO, 2008b).

Não é fácil delimitar conceitualmente cada um desses eixos de conteúdos propostos, dada a sutileza de suas semelhanças, diferenças e interações. A capoeira é um exemplo esclarecedor. Ao mesmo tempo é luta, jogo e dança, tem sido objeto de um processo de "esportivização", e no seu próprio interior possui ao menos duas manifestações que se distinguem em alguns aspectos - a capoeira angola e a capoeira regional (SEE/SP, 2008, p. 44).

Segundo os PCN (BRASIL, 1998), a Educação Física, como área de saber 
centrada na cultura corporal do movimento, possui uma gama de conteúdos ou estratégias de ação que podem contribuir efetivamente para a abordagem da temática em questão, seja na concepção conceitual, procedimental ou atitudinal.

\section{ANÁLISE DO MATERIAL DIDÁTICO PROPOSTO PELO GOVERNO DO ESTADO DE SÃO PAULO}

Em 2008, a Secretaria da Educação do Estado de São Paulo lançou uma proposta curricular para os níveis de ensino Fundamental - Ciclo II e Médio, para ser implementada de forma imediata em todas as escolas da rede pública do Estado de São Paulo (SEE/SP, 2008).

Essa proposta tem como meio de ação o material que é entregue gratuitamente aos alunos, o chamado "Caderno do Aluno", que foi dividido em áreas, tais como: Ciências da Natureza e suas Tecnologias; Matemática e as áreas do conhecimento; Ciências Humanas e suas Tecnologias e Linguagens, Códigos e suas Tecnologias, na qual a Educação Física está inserida (BRASIL, 1998).

Segundo Marques et. al. (2009), o caderno do aluno também é dividido por disciplina/série/bimestre e possui uma disposição de textos, figuras e gráficos semelhantes aos do professor, porém, com espaços para responderem no mesmo caderno, dicas de pesquisas filmes, livros e sites.

De acordo com a Proposta Curricular do Estado de São Paulo a Educação Física não se reduz apenas ao condicionamento físico e ao esporte, mas introduz o aluno nas diferentes manifestações culturais (OLIVEIRA, 2012).

O aluno do Ensino
Fundamental e do Médio
deve não só vivenciar,
experimentar, valorizar,
apreciar e aproveitar os
benefícios advindos da
cultura do movimento, mas
também perceber e
compreender os sentidos e
significados das suas
diversas manifestações na
sociedade contemporânea
(SSE/SP, 2008, p. 38).

O conteúdo para a disciplina de Educação Física do Ensino Fundamental Ciclo - II, dentro da Proposta Curricular do Estado de São Paulo, está contemplado de uma temática voltada para a aplicação e valorização da história e cultura afrobrasileira e africana.

Ao analisar todo o material, do $6^{\circ}$ ao $9^{\circ}$ ano, nos seus quatro volumes, divididos por bimestre, notou-se que o material da $8^{a}$ série ou 9ㅇa ano do Ensino Fundamental, dispõe desse conteúdo materializado no ensino da capoeira, ministrado no Volume 1, como Tema 1- Luta - Capoeira, da página 05 a 16. 
Nas orientações gerais contidas no caderno para a $8^{\circ}$ série $/ 9^{\circ}$ ano, direcionadas ao aluno, a equipe curricular antepõe o assunto capoeira, referindo-se a ela como luta, jogo, dança e atividade rítmica:

No tema "Luta", o conteúdo será a capoeira. Essa modalidade é bastante tradicional e tem sido difundida no Brasil desde o período colonial. É repleta de significações e representações, mostradas em seus elementos de luta, jogo, canto e atividade rítmica. A capoeira é uma manifestação popular que vem ganhando espaço na disciplina de Educação Física (SEE/SP, 2014, p. 03).

No entanto, não a valoriza no que tange a dimensão social e meio de construção da identidade nacional e pessoal, valorizando a pluralidade, e posicionando os alunos de maneira crítica visando a defesa da “discriminação baseada em diferenças culturais, de classe social, de crenças, de sexo, de etnia ou outras características individuais e sociais" (BRASIL, 1998)

Após essas orientações, o caderno introduz o tema "Capoeira" fazendo em seu primeiro tópico/texto uma ênfase à resistência do negro: "Falar da história da capoeira brasileira é reportar-se à história da resistência dos negros no Brasil" (SEE/SP, 2014, p 05).
Ainda de acordo com o texto, os negros trouxeram consigo suas tradições culturais, representando- as na dança e no divertimento para treinar seus movimentos e fugir do cativeiro, dispondo do Quilombo dos Palmares como berço dessa luta (SEE/SP, 2014, p 05).

Segundo o texto, os grupos de capoeira, ou capoeiristas, simbolizam a "força negra nos tempos da escravidão", e há aqueles que a veem como luta, manifestação folclórica, esporte ou aspecto educativo:

Os grupos costumam
interpretar a capoeira de
maneiras distintas, alguns
trabalham a capoeira numa
visão mais folclórica, outros
entendem que a
modalidade é uma forma de
luta; alguns dão maior
ênfase à parte esportiva,
outros valorizam,
principalmente, o aspecto
educativo (SEE/SP, 2014, p
05).

Não obstante a isso, a origem da capoeira não foi esplanada nesse texto, bem como os benefícios advindos de sua prática, das capacidades afetiva, física, cognitiva, ética, estética, de interrelação pessoal e de inserção social, propostas nos objetivos dos Parâmetros Curriculares Nacionais voltados para os terceiro e quarto ciclos do Ensino Fundamental (BRASIL, 1998).

A partir da página seguinte, 06 , até a página 12 , o caderno traz ilustrações de 
alguns dos instrumentos utilizados na roda de capoeira para que os alunos os identifiquem. Em seguida, como lição de casa, a proposta é que o aluno tente exercitar os movimentos que caracterizam a capoeira, seguindo um passo a passo, e apresenta a sugestão de convidar alguns amigos para praticar junto. Por fim, a proposta é que os alunos identifiquem as imagens dos movimentos da capoeira e indiquem o nome de cada uma delas, além de realizar uma pesquisa de campo em busca de músicas utilizadas na roda de capoeira.

Antes de tudo, o caderno não apresenta nenhum conteúdo referente aos instrumentos, músicas ou movimentos da capoeira, que conduza os alunos a executarem de forma eficaz as atividades sugeridas, em especial à lição de casa, na qual os movimentos deveriam ser demonstrados pelo professor.

O caderno ainda contém uma breve explicação sobre os dois estilos da capoeira, a capoeira de angola e a regional, e algumas dicas de filmes e sites para os alunos se aprofundarem no tema. Ao final de cada tema, o caderno do aluno faz um questionário sobre o que o aluno aprendeu no tema proposto.

$\mathrm{Na}$ conclusão do tema Capoeira, o caderno faz uma correlação da capoeira com a postura corporal, advertindo o aluno sobre sua importância.
Os Parâmetros Curriculares Nacionais (1998) trazem como uma das características da área de Educação Física a pluralidade cultural, que permite com que os alunos vivenciem diferentes práticas corporais advindas das mais diversas manifestações culturais, mostrando a variedade de influências que o Brasil tem nas danças, os esportes, as lutas, os jogos e as ginásticas:

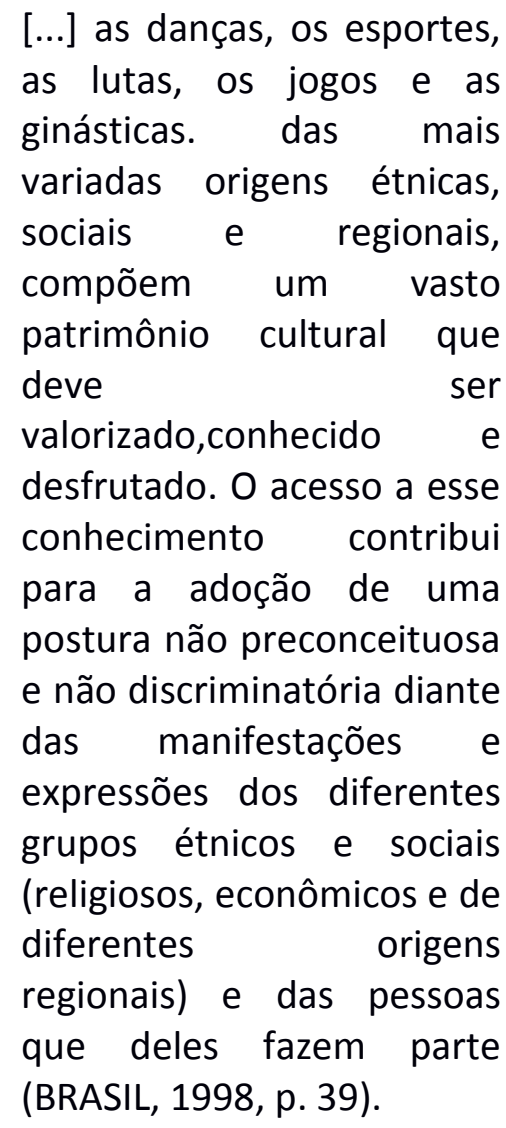

A partir destas características e da realidade do ensino de cultura africana nas instituições escolares dentro da grade curricular do Ensino Fundamental, a Educação Física, como disciplina obrigatória e promotora da cultura corporal de movimento e inclusão de temas como, cidadania, ética, valores e conceitos e pluralidade cultural, 
pode viabilizar a lei no 10.639/2003 (temática afro-brasileira), materializada no ensino da capoeira (BRASIL, 1998, p. 12).

\section{CONCLUSÃO}

Neste trabalho, foi elaborado um levantamento bibliográfico acerca da aplicação da Lei no 10.639/2003 que propõe o ensino da história e cultura afro-brasileira e africana nos currículos das escolas de Ensino fundamental e Médio, por meio das aulas de Educação Física materializada no ensino da capoeira.

Foi analisado também o conteúdo do material didático do Governo do Estado de São Paulo destinado ao Ensino Fundamental Ciclo - II para a disciplina de Educação Física.

Pôde-se observar que, na $8^{\text {a }}$ série $/ 9^{\circ}$ ano do Ensino Fundamental, a capoeira está incorporada à Proposta Curricular, sendo uma forma de efetivação da lei em questão.

Ao fazer uso dos objetivos da Educação Física inseridos nos PCN, direcionados ao Ensino Fundamental, concluímos que é possível trabalhar a cultura afro-brasileira, tendo a capoeira como forma de inserção da lei na grade curricular, e essa é a realidade do ensino.

Entretanto, a capoeira ainda não é tratada de forma integral, abrangendo todos os aspectos que a ela compete, em nível histórico-social, motor, cognitivo e sua contribuição para a valorização da cultura negra.

Almejamos que os profissionais e futuros profissionais de Educação Física possam difundir no ambiente acadêmico e, principalmente no ambiente escolar, a discussão e a aplicação da capoeira como meio de valorização da cultura africana e afro-brasileira.

\section{REFERÊNCIAS}

ABRAMOWICZ, A. Trabalhando a diferença na educação infantil. São Paulo: Moderna. 2006.

ALBUQUERQUE, R.; WALTER, F. Uma história do negro no Brasil. Brasília: Fundação Cultural Palmares,, 2006.

ARAUJO, H. L. E.; FONSECA, A. C. Capoeira e Cidadania: Seu poder e atuação como instrumento educacional em ambiente escolar. Revista Eletrônica da Faculdade Metodista Granbery, n. 9, 2010. Disponível em:. http://re.granbery.edu.br.

BRASIL. Constituição (1988). Lei Federal $n^{\circ}$ 9.394, de 20 de dezembro de 1996. Diretrizes e Bases da Educação Nacional. Diário Oficial da União, Brasília: Gráfica do senado, 1995.

BRASIL. História e Cultura Afro Brasileira. Lei no 10.639, de 9 de janeiro de 2003.

BRASIL. Secretaria de Educação Fundamental.Parâmetros curriculares nacionais: Educação Física/ Brasília: MEC /SEF. 1998. 114 p.

BRASIL. Secretaria de Educação Fundamental. Parâmetros curriculares nacionais: Educação Física.Brasília : MEC /SEF, 1998. 114 p. 
CAVALLEIRO, E. S. Do Silêncio do Lar ao Silêncio Escolar: Racismo, preconceito e discriminação na educação infantil. São Paulo: Contexto., 2007.]

COSTA, L. C. A.; NASCIMENTO, J. V. Prática Pedagógica de Professores de Educação Física. Conteúdos e abordagens pedagógicas, Maringá, v. 17, n. 2, p. 161-167,. 2006.

DARIDO, S. C. Educação Física na Escola: Realidade, aspectos legais e possibilidades. Universidade Estadual Paulista. Prograd. Caderno de formação: formação de professores didática geral. São Paulo: Cultura Acadêmica, v. 16, p. 21-33, 2012., Disponível em:

<http://www.acervodigital.unesp.br/handle/ 123456789/41548>. Acesso em: 12 abr. 2014.

DARIDO, S. C.; RANGEL, I. C. A. Educação Física na Escola: Implicações para a prática pedagógica. Rio de Janeiro: Guanabara Koogan, 2005.

EHRENBERG, M. C.; FERNANDES, R. C. A Capoeira nas Aulas de Educação Física Escolar: Vivências e possibilidades no ensino fundamental. In: XVI Endipe. ENCONTRO NACIONAL DE DIDÁTICA E PRÁTICAS DE ENSINO. UNICAMP. Campinas. 2012.

GIL, A. C. Métodos e Técnicas de Pesquisa Social. 6. ed. São Paulo: Atlas, 2008. GOVERNO DO ESTADO DE SÃO PAULO. Proposta Curricular: Educação física. São Paulo: SEESP. 2008.

MAZZOTTI, J. A.; GEWANDSZNAJDER, F. O Método nas Ciências Naturais e Sociais: Pesquisa quantitativa e qualitativa.2.e.d São Paulo: Pioneira, 1999.

OLIVEIRA, L. M. O Ensino da História e Cultura Afro-Brasileira e a Educação Física: Um estudo sobre o currículo vivido em Santo André. São Paulo. 2012.
OLIVEIRA SILVA, T. F. Lei 10.639/03: por uma educação antirracismo no Brasil. 2012.

REIS, M. C. O Processo Civilizador na Construção da Identidade Negra. UFPE, Programa de Pós-Graduação em Educação. 2009.

SANTOS, L. S. Educação - Educação física Capoeira. Maringá: Fundação Universidade Estadual de Maringá, 1990.

SECRETARIA DA EDUCAÇÃO DO ESTADO DE SÃO PAULO. Edição Especial da Proposta Curricular. Revista do Professor. IMESP. São Paulo. 2008.

SEVERINO, A. J. Metodologia do trabalho científico. 23. ed. .. São Paulo: Cortez, 2007.

SILVA, A. História e Cultura Afro-Brasileira: Caminhos pedagógicos abertos pela lei federal no. 10.639/03, no combate ao preconceito racial. UFPB-PRG. In: ENCONTRO DE INICIAÇÃO À DOCÊNCIA, 11., 2007.

SILVA, G. De O.; HEINE, V. Capoeira: um instrumento psicomotor para a cidadania. São Paulo: Phorte, 2008.

SOUZA, E. G. R. S.; FERRAZ, M. RHistória e Cultura Afro-brasileira (lei № 10.639/2003): Um desafio para a educação física escolar. XI EnFEFE - Encontro Fluminense de Educação Física Escolar. 2007. Disponível em: <http://cev.org.br/biblioteca/historiacultura-afro-brasileira-lei-n-10639-2003-umdesafio-para-educacao-fisica-escolar/>. Acesso em: 12 abr. 2014.

SOUZA, M.; JESUS, M.; CRUZ, T. História e Cultura Afro-Brasileira na Escola: Lei 10.639/03. Revista Eletrônica da Faculdade José Augusto Vieira, v.5, n. 7. Disponível em: <http://fjav.com.br/revista/Downloads/edica o07/Historia_e_Cultura_AfroBrasileira_na_Es cola.pdf>. Acesso em: 12 abr. 2014.

SOUZA, S. A. R.; OlIVEIRA, A. A. B. Estruturação da Capoeira Como Conteúdo da 
Educação Física no Ensino Fundamental e Médio. Revista da Educação Física, Maringá, v.. 12, n. 2, p. 43-50,2001.

Recebido para publicação em 16/08/2014

Aceito em 02/09/2014 